\title{
Leveraging technology and supply chain to improve family planning logistics in Pakistan
}

Muhammad Tariq, ${ }^{1}$ Ambreen Khan ${ }^{1}$ and Kayhan Motla ${ }^{1}$

${ }^{1}$ USAID Global Health Supply Chain Program, Procurement and Supply Management, National Science and Technology Park, Islamabad, Pakistan (Correspondence to: Muhammad Tariq: mtariq@chemonics.com).

\begin{abstract}
Background: Pakistan and USAID have invested in improving the contraceptive supply chain data and commodity security. In 2011, the first digital contraceptive logistics management information system (cLMIS) was launched, enabling supply chain data visibility from the federal level to health facilities. The system has built-in modules on forecasting and supply planning, inventory management, consumption reporting, business intelligence tools, automatic email and SMS alerts. Using these features, policy-makers and health managers annually forecast needs, and procure contraceptives accordingly.

Aims: The objective of this research was to understand the existing technological platforms for family planning (FP) supply chain data visibility and the potential impact on contraceptive commodity security.

Methods: The authors reviewed available published and grey literature papers on contraceptives and supplies in Pakistan. We extracted data from the cLMIS, evaluated indicators including reporting compliance, reported stock-out rates, and contraceptive performance. The analysis was validated by reviewing supply chain and FP indicators, such as average monthly consumption, months of stock, and couple years of protection.

Results: The cLMIS has resulted in improved distribution, early warning and accountability at the lowest tiers in the FP supply chain in the public sector. At the facility level, FP commodity availability increased from $40 \%$ in 2009 to $84 \%$ in 2018 .

Conclusion: Contraceptive supply chain has seen significant growth over the past decade to meet expanding reproductive health evidence to inform strategic decisions; cLMIS is a prime contributor to improvements registered in FP stock availability at public sector facilities.

Keywords: logistics management information system, family planning commodities, data visibility, stock availability

Citation: Tariq M; Khan A; Motla K. Leveraging technology and supply chain to improve family planning logistics in Pakistan. East Mediterr Health J. 2021;27(7):672-678. https://doi.org/10.26719/2021.27.7.672

Received: $27 / 10 / 20$, accepted: 14/01/21
\end{abstract}

Copyright (C) World Health Organization (WHO) 2021. Open Access. Some rights reserved. This work is available under the CC BY-NC-SA 3.0 IGO license (https://creativecommons.org/licenses/by-nc-sa/3.o/igo).

\section{Introduction}

Through enabling people to determine the number and spacing of their children, contraception offers a range of potential benefits, including contributing to economic development, improved maternal and child health, and being a source of women's empowerment (1).

Despite increases in contraceptive use, an estimated 214 million women of reproductive age had an unmet need for contraception in low- and middle-income countries in 2017 (2). Reducing unmet need for modern contraception by increasing the access to and supply of contraceptives has been a critical area of interest in reproductive health for decades (2). It is key to meeting the family planning (FP) 2020 goal of enabling an additional 120 million women and girls in the world's poorest countries to be using modern methods of family planning by 2020 (3). Thus, the objective of this research was to understand the existing technological platforms for FP supply chain data visibility and the potential impact on contraceptive commodity security.

Although there has been a national FP programme since the 1960s, there has been limited progress in
Pakistan. The country faces rapid population growth, with projections that by 2050 the population will surpass 310 million from 207.7 million currently (4). A signatory to the global FP2020 pledge (5), Pakistan is committed to reducing its population growth rate by increasing the contraceptive prevalence rate from $34.2 \%$ in $2017-18$ to $50 \%$ by 2020 ; however, modern contraceptive use by married women has remained stagnant over the past 5 years, with $26 \%$ of women using a modern method in 2012-13 (6) and 25\% in 2017-18 (7). Among the modern method mix, there was negligible difference in the use of all methods over time.

Even with substantial efforts, Pakistan's health and population departments struggle to steward dynamic FP programmes. The primary hindrance in successfully implementing FP programmes remains a lack of coordination among government run health and population welfare departments, planning and finance divisions, and public and private stakeholders (8).

In 2010, provincial departments of population welfare were moved to the administrative control of the provinces and became administratively independent from the Ministry of Population and Welfare. This administrative 
change did not create significant improvement in health systems (9); even with support from donors and nongovernmental organizations, supply chain systems remained ad hoc and fragile. A 2014 qualitative study showed frequent stock-outs and interrupted supplies decreasing access to FP (6). Requisitioning contraceptives from different departments/stakeholders, poor supply mechanisms, lack of transportation financing, inadequate planning, procurement delays and the lack of a monitoring and supervision framework compounded the challenges (6). Before 2011, the system was inadequate owing to the lack of a standardized logistics management information system (LMIS) for FP products (10).

Lack of access and lack of availability caused by supply chain failures are among the principal reasons for contraceptive non-use and contraceptive discontinuation (11). Supply chain management comprises the steps involved in moving a product from the supplier to the customer (12). Research has identified distribution system inefficiencies and lack of institutionalized LMISs as critical barriers to effective contraception supply chains in low- and middle-income countries (13). For example, Morocco's highly complex "pull-based" supply chain system involved excessive steps and relied on the accuracy of 900 minimally-trained midwives at service delivery points to make contraception forecasts (14). The system required facilities to pick up supplies from the warehouse at their own expense, and many facilities kept poor inventory records. In Senegal, Daff et al. contend that inefficiencies in the public health supply chain system contributed to a lack of accurate and timely data hindering the existence of a well-functioning supply chain system (15). These examples illustrate that the absence of robust public health supply chains systems leads to unreliable data and inaccurate forecasts and procurements, which can impact the product availability at the last mile.

Prior to the implementation of the contraceptive logistics management information system (cLMIS) in Pakistan, the reported clients, via service delivery point data and observed by surveys, showed major differences. The contraceptive performance reports published by the Pakistan Bureau of Statistics depended on the collation of the manual records available in the warehouse, and even then showed some inconsistencies (Tables 1,2).
Recognizing these issues, the Government of Pakistan looked at options available to resolve the discrepancies and streamline the system. In Pakistan, prior to 2008, contraceptives were supplied via the Central Warehouse's manual record keeping system, leading to errors and delays. In response to a request from the health ministry in 2008, this manual record keeping system was replaced by an online system, the cLMIS. It was developed as a result of cooperation between the Ministry of National Health Services, Regulations and Coordination, the provincial departments of health and the population welfare departments with support from the United States Agency for International Development (USAID) (16).

In July 2011, during the first phase of implementation, 19 districts (out of 143 total) across Pakistan were equipped with the system. Staff were trained, and pilot testing carried out to verify that the new system would improve data visibility, enabling effective stock monitoring. By 2012, it had been scaled up nationally and was used in all 143 districts. With USAID support, around 1000 government staff in provincial health and population welfare departments received training on how to use the CLMIS (17).

This cLMIS collects, organizes and reports data, and generates analytics to facilitate improved policy decisions. The system enables supply chain data visibility of all contraceptive health commodities for the public sector and nongovernmental organizations. With the introduction of the web-based cLMIS, managers, logisticians and donors have better visibility into the supply chain and can thus improve their management to ensure products reach consumers through Pakistan's health care delivery system. The cLMIS allows authorized users at various locations to enter logistical data and access cLMIS reports through a web browser. Reports include stock status, months of stock and other information critical to supply chain functioning. By improving the timeliness and quality of logistics data and reducing the time needed to access the data, the cLMIS effectively enables evidence-informed decision-making for supply chain management (17).

\begin{tabular}{|c|c|c|c|c|c|c|c|c|}
\hline \multirow[t]{2}{*}{ Type } & \multicolumn{7}{|c|}{ Year } & \multirow{2}{*}{$\begin{array}{c}\text { Difference } \\
2011-2018 \\
(\%)\end{array}$} \\
\hline & $2011-12$ & $2012-13$ & 2013-14 & 2014-15 & $2015-16$ & 2016-17 & 2017-18 & \\
\hline Condoms & 1.49 & 1.88 & 1.93 & 2.58 & 2.73 & 2.74 & 2.71 & $1.22(44.9)$ \\
\hline Oral pills & 0.48 & 0.50 & 0.52 & 1.15 & 1.15 & 1.47 & 1.30 & $0.82(63.1)$ \\
\hline Intra-uterine device (insertions) & 1.32 & 1.23 & 1.67 & 1.79 & 1.82 & 1.89 & 1.83 & $0.51(28.1)$ \\
\hline Injectable (vials) & 0.54 & 0.58 & 0.56 & 1.46 & 1.31 & 1.85 & 1.63 & $1.09(66.9)$ \\
\hline Contraceptive surgery (sterilization) & 0.12 & 0.10 & 0.11 & 0.22 & 0.19 & 0.17 & 0.17 & $0.05(31.2)$ \\
\hline Total & 3.95 & 4.29 & 4.80 & 7.20 & 7.19 & 8.12 & 7.64 & $3.69(48.3)$ \\
\hline
\end{tabular}

Source: Pakistan Bureau of Statistics. Annual contraceptive performance reports from the years 2011-12 to 2017-18. 


\begin{tabular}{|c|c|c|c|}
\hline Type & $\begin{array}{c}\text { Service } \\
\text { delivered }^{a}\end{array}$ & $\begin{array}{l}\text { Service } \\
\text { uptake }^{\text {b }}\end{array}$ & Difference \\
\hline Condoms & 2.71 & 9.20 & -6.49 \\
\hline Oral pills & 1.30 & 1.70 & -0.40 \\
\hline $\begin{array}{l}\text { Intra-uterine device } \\
\text { (insertions) }\end{array}$ & 1.83 & 2.10 & -0.27 \\
\hline Injectable (vials) & 1.63 & 2.50 & -0.87 \\
\hline $\begin{array}{l}\text { Contraceptive surgery } \\
\text { (sterilization) }\end{array}$ & 0.17 & 8.90 & -8.73 \\
\hline Total & 7.64 & 24.40 & -16.76 \\
\hline
\end{tabular}

aFrom the Contraceptive Performance Report 2017-18.

${ }^{b}$ From the Pakistan Demographic and Health Survey 2017-18 (sterilization includes 8.8 for women and 0.1 for men).

\section{Methods}

The authors reviewed papers on contraceptive use and logistics, both published and grey literature, relating to Pakistan as well as the contraceptives performance reports compiled by the Pakistan Bureau of Statistics and the Pakistan Demographic and Health Surveys $(6,8,18)$. In addition, data was extracted from the cLMIS, focusing on such indicators as reporting rate and stock availability ratios. The data extracted from cLMIS included indicators on data reporting compliance, reported stock-out trends and contraceptive performance (Figure 1).

Stock availability and reporting rates from 2015-2018 were compared. The study was conducted considering one stakeholder, the population welfare departments, in all 4 provinces. The population welfare department is the main stakeholder in contraceptive service delivery for the public sector and the not-for-profit private sector.

\section{Results}

Systems reporting compliance improved over the years, showing increased contraceptive performance and improved stock availability at the service delivery points. Quantitative data obtained from cLMIS were used for time series analysis of reporting rates as well as data use and stock availability. Stock availability and reporting rates over 4 years (2015-2018) were compared (Figure 2). The graph shows the stock availability of 4 products, condoms, pills, intrauterine contraceptive devices and injectables, for 2015-2018. The data usage indicator was developed to ascertain that supply decisions were in line with stock availability at service delivery points. The reporting rate and data use increased from $71 \%$ to $99 \%$ and stock availability increased from $86 \%$ to $91 \%$. The analysis confirms that, with improved data visibility through the LMIS, decision-makers were able to take decisions on allocation of funds for contraceptive procurement, leading to improved stock availability. The availability of supplies in the public sector has led to an increase in the share of services provided for condoms, intrauterine contraceptive devices and injectables.

\section{Discussion}

The main purpose of an improved supply chain is to ensure commodity availability (19). The cLMIS reduced paper-based reporting and optimized health systems data reconciliation at the health facility level. Timely reporting at the district and union council level (lowest administrative tier of the government) is essential to ensuring superior stock monitoring from procurement to "lastmile".

Web-based end-to-end dashboards made the cLMIS data for the entire supply chain visible to government decision-makers, including but not limited to the health secretariat and federal and provincial health ministries. These powerful analytics inform the relevant authorities to take timely actions for stock replenishments at district and health facility levels. One key example would be the FP executive dashboard, which informs the decisionmakers at the provincial and district levels where service delivery point stocks have gone below the agreedupon levels, posing a risk of stock-out. The system also automatically generates stockout emails and SMS alerts, enabling relevant officials to take timely decisions.

The FP executive dashboard was developed to provide an overview of stock sufficiency for FP commodities in

Figure 1 The framework demonstrating the Pakistan contraceptive logistics management information system (LMIS)-driven data visibility

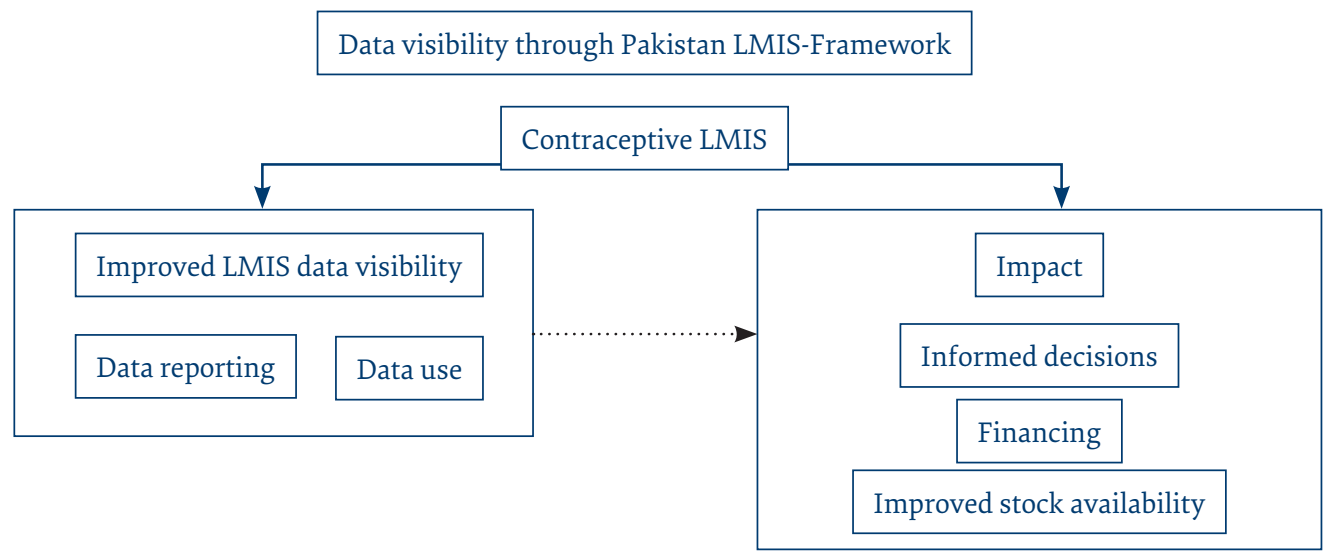


all 4 provinces, relevant districts and service delivery points/health facilities. In each province, the health and population welfare departments are the main consumers of FP commodities, and in some provinces, such as Sindh, both departments are procuring jointly with storage at the Central Warehouse and Supplies in Karachi. Thus, the dashboard not only provides a real-time stock situation at the Central Warehouse \& Supplies but also the pipeline for each product, enabling users to observe the stock situation for a particular commodity at the service delivery point level (20).

It is worth noting that data reporting in the districts and health facilities is compiled on a monthly basis. Consequently, the stock data for districts and health facilities will be displayed in the upcoming month, i.e. data related to March will be displayed in April after data entry has been completed. By requiring that data for a given month be reported before the 1oth of the upcoming month, data visibility is greatly improved. This monthly reporting also accurately calculates reordering dates such that stock sufficiency levels are maintained, minimizing the possibility of future stock-outs.

The stock-out rate is defined as the number of service delivery points that, at any point, in a defined period (e.g. the past 3, 6 or 12 months), experience a stock-out of a specific FP tracer product that the service delivery point is expected to provide. The web-based end-to-end dashboards display the months of stock for each product using different colours to identify the level of severity with respect to replenishing the stock. This provides users with intelligence for when and how much a particular product needs to be ordered in the future to maintain the desired maximum stock levels.

Increased data visibility through cLMIS enabled policy-makers and managers to take evidence-informed and timely decisions, particularly in terms of replenishing stock. This was supported by the system's ability to generate automatic email and SMS alerts to policymakers and managers. For example, based on district consumption trends generated from LMIS data, all 4 provinces (Balochistan, Khyber Pakhtunkhwa, Punjab,
Sindh) and other regional governments committed more than \$US 130 million during 2014-2020 for FP commodity procurement, with an average of \$US 20 million per year compared with \$US 5 million per year before (2001-2009) (32). Technology improved the data visibility for cLMIS helping policy-makers make timely and better decisions.

Nationally speaking, there are a total of 20503 active service delivery points in Pakistan; 5030 fall under the purview of the population welfare department, 12940 under the provincial departments of health, and 2533 under the People's Primary Healthcare Initiative. Based on cLMIS data and improved reporting compliance, the contraceptive method mix shifted towards long-term methods, including intrauterine devices and implants. The national consumption of intrauterine contraceptive devices increased from $0.96 \mathrm{~m}$ in 2015 to $1.05 \mathrm{~m}$ in 2018 , and implants from $0.033 \mathrm{~m}$ in 2015 to $0.075 \mathrm{~m}$ in 2018 (www.lmis.gov.pk). The stock-out trend analysis showed that the increase in supply data was accompanied by an increase in stock availability, i.e. an increase of stocks present at the service delivery point.

The trend escalated further after automatic stock alerts were generated to managers/policy-makers through email and SMS, which was first introduced in 2018. The stock availability rate reported in 2018 was 91\% (Figure 2). This was mainly due to resource mobilization by the provincial governments for contraceptive procurement along with timely initiation of procurements contingent upon LMIS based quantification. Around 5000 alerts generated in 2018-19 enabled policy-makers to take timely actions to avert stock-outs; however, the use of data and alerts is an incremental journey (23).

The paper-based reporting system was automated, leading to better maintained and more accurate records and the removal of duplication of efforts. Political ownership and support by senior leadership for cLMIS helped to achieve timely data reporting and ensure data quality, leading to effective decision-making (24). The provincial authorities issued notifications to the districts for reporting compliance, which enabled timely visibility of data (25).

Figure 2 Comparison of data use and stock availability for condoms, pills, intrauterine contraceptive devices and injectables in Pakistan, 2015-2018

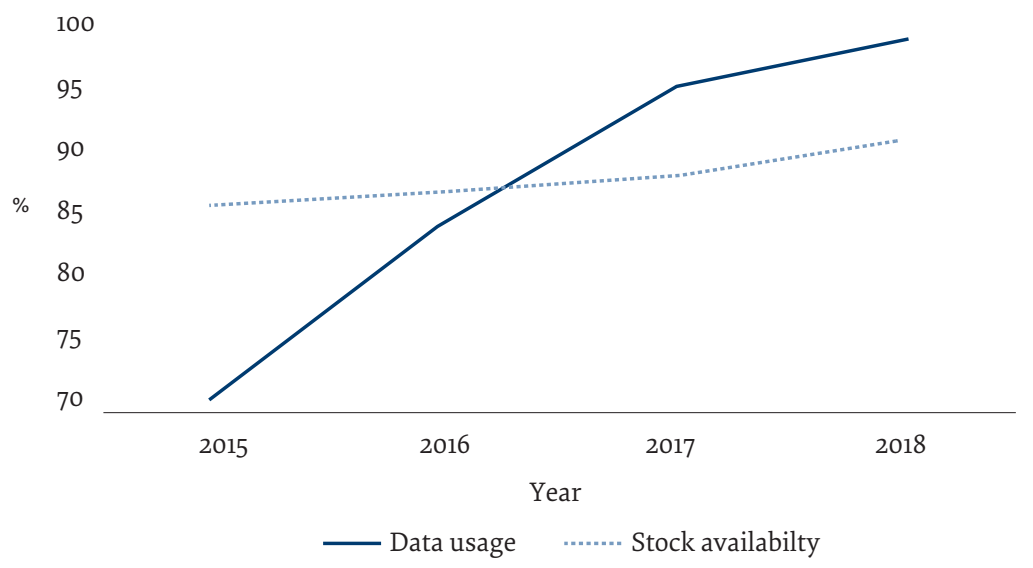


The stock-out rate decreased from $14 \%$ to $9 \%$ (Figure 2) due to improved access to accurate, timely and reliable inventory information. Data were used to support improved forecasting, which was formerly based on manually compiled consumption data, usually one-yearold data. Accurately estimating forecasted need is key to ensuring that the correct quantities of contraceptives are procured to provide a regular, uninterrupted supply of commodities (26). This in turn supported clear costing of the FP commodity needs. These demand and financing requirements were calculated based on data obtained from cLMIS that led to better financial management and timely procurement of FP commodities. The LMIS reporting enabled measurement of the modern contraceptive prevalence rate based on a couple of years' protection generated, which was impossible previously (22).

Despite improving the reporting rates and stock availability, Pakistan's cLMIS, as is the case in many other low- and middle-income countries, still faces challenges, including a lack of integration. The cLMIS needs to be linked with the district health information system or the national health management information system (6); integration would enable better coordination and delivery of services and supplies of FP (27).

Another challenge is sustainability. There is still no health information and communication policy which could serve as a guideline for digitizing the health sector, avoiding duplication of efforts and leveraging technology for evidence-informed decision-making (28). There also remains a lack of trained human resources (29). Management issues like calibrating stock (to avoid stockouts or overstocking) as well as lack of communication and interdepartmental coordination also complicate efforts $(19,30)$. Other issues include inconsistencies in reporting meaning the system is unable to identify exact demand (6). Finally, there are challenges around financing for delivering FP products from the district warehouses to the health facilities. Strengthening supply chains to meet the growing demand for FP will require systems diagnostics, supply chain redesign or adjustment, strategically located storage and distribution systems, adequate staffing and training, and better information about inventory and financing (31). To help address these challenges, there is a need to bring all stakeholders together to have and use a single platform for an integrated health information system where services, surveillance, demographic and logistic data streams intersect in addition to health information and communication policy.

\section{Conclusion}

With USAID support, the Pakistan FP supply chain has expanded over the past decade from $\$ 5 \mathrm{~m}$ to around $\$ 20 \mathrm{~m}$ spending per year (21). This growth has been accelerated by providing decision-makers with the evidence needed to make timely strategic decisions. However, the system is still experiencing challenges such as frequent stockouts and a lack of contraceptives, which has a negative impact on programme effectiveness and quality of care, resulting in a loss of trust in the overall health system (32). Technology-driven data visibility alone is insufficient; for real change to happen, data must be analysed and used for routine and strategic decisions and for continuous quality improvement. Against this backdrop, cLMIS indisputably stands out by improving FP stock availability at the last mile.

Funding: None.

Competing interests: None declared.

\section{Mettre à profit la technologie et la chaîne d'approvisionnement pour améliorer la logistique de la planification familiale au Pakistan \\ Résumé}

Contexte : Le Pakistan et l'USAID ont investi dans l'amélioration des données de la chaîne d'approvisionnement en contraceptifs et de la sécurité des produits. En 2011, le premier système numérique d'information pour la gestion de la logistique des contraceptifs a été lancé, permettant la visibilité des données de la chaîne d'approvisionnement depuis le niveau fédéral jusqu'aux établissements de santé. Le système comprend des modules intégrés de prévision et de planification de l'approvisionnement, de gestion des stocks, de rapports de consommation, d'outils de veille stratégique, d'alertes automatiques par courriel et par SMS. En utilisant ces options, les responsables de l'élaboration des politiques et les responsables de la santé peuvent prévoir les besoins chaque année et en conséquence se procurer des contraceptifs.

Objectifs : L'objectif de la présente recherche était de comprendre les plateformes technologiques existantes pour la visibilité des données de la chaîne d'approvisionnement pour la planification familiale et l'impact potentiel sur la sécurité des produits contraceptifs.

Méthodes: Nous avons passé en revue les articles disponibles publiés et la littérature grise sur les contraceptifs et les fournitures au Pakistan. Nous avons extrait les données du système numérique d'information pour la gestion de la logistique des contraceptifs, évalué les indicateurs, notamment la conformité des rapports, les taux de rupture de stock rapportés et la performance des contraceptifs. L'analyse a été validée par l'examen de la chaîne d'approvisionnement et des indicateurs de planification familiale, tels que la consommation mensuelle moyenne, les mois de stock et le couple-années de protection. 
Résultats: Le système numérique d'information pour la gestion de la logistique contraceptive a amélioré la distribution, l'alerte précoce et la responsabilisation aux niveaux les plus bas de la chaîne d'approvisionnement en planification familiale dans le secteur public. Au niveau des établissements, la disponibilité des produits de planification familiale est passée de $40 \%$ en 2009 à $84 \%$ en 2018 .

Conclusion: La chaîne d'approvisionnement en contraceptifs a connu une croissance significative au cours de la dernière décennie pour répondre à l'augmentation des bases factuelles en matière de santé reproductive afin d'informer les décisions stratégiques. Le système numérique d'information pour la gestion de la logistique des contraceptifs joue un rôle important dans les améliorations de la disponibilité des stocks de planification familiale dans les établissements du secteur public.

$$
\begin{aligned}
& \text { الاستفادة من التكنولوجيا وسلسلة الإمداد في تحسين لوجستيات تنظيم الأسرة في باكستان } \\
& \text { محمد طارق، أمبرين خان، كيهان موتلا }
\end{aligned}
$$

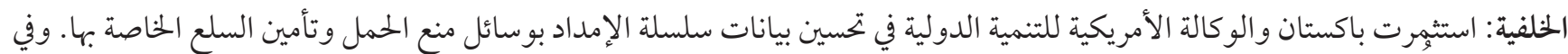

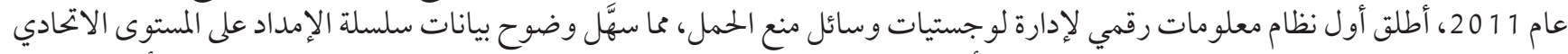

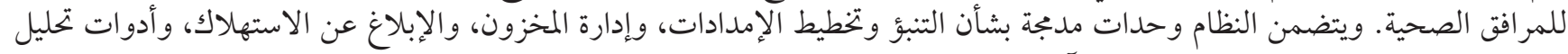

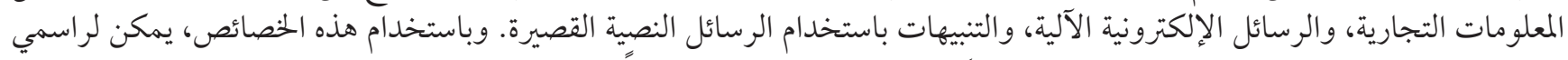

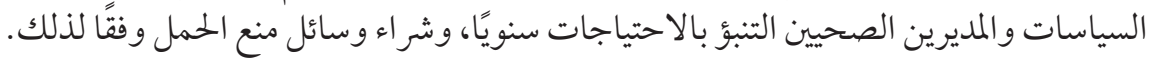

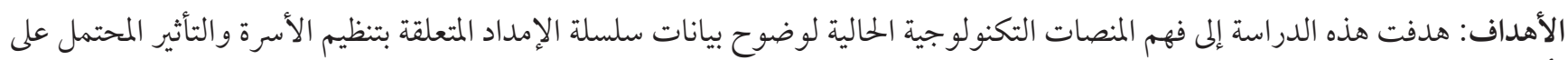
تأمين السلع الخاصة بوسائل منع الحمل.

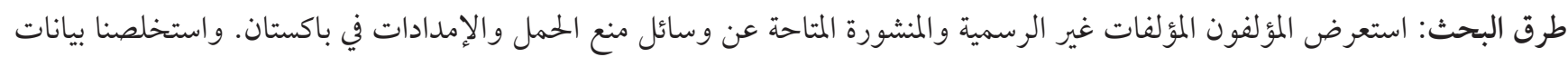

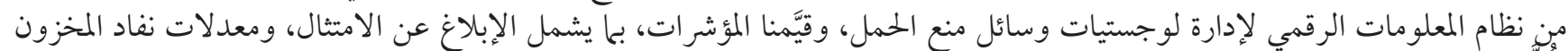

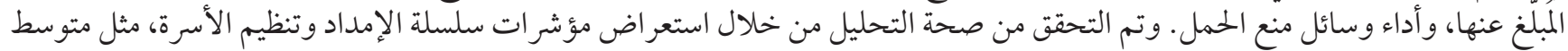
الاستهلاك الشهري، وشهور المخزون، وفنترة الحماية من الإنجاب.

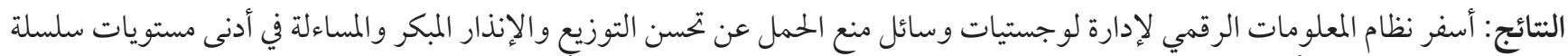

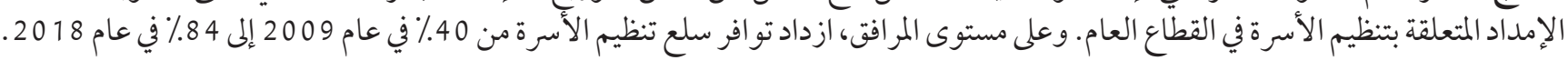

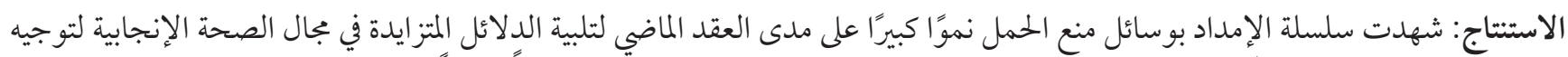

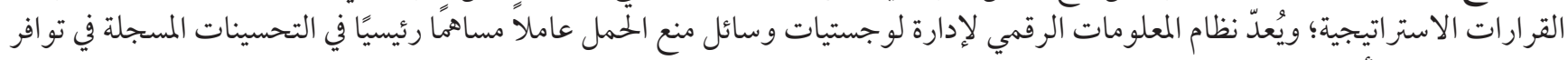
مخزونات تنظيم الأسرة في مر افق القطاع العام.

\section{References}

1. Cleland J, Conde-Agudelo A, Peterson H, Ross J, Tsui A. Contraception and health. Lancet. 2012;380:149-56. doi:10.1016/So1406736(12)60609-6

2. Family planning/contraception methods. Geneva: World health Organization; 2020 (https://www.who.int/news-room/factsheets/detail/family-planning-contraception, accessed 21 February 2021).

3. Alkema L, Kantorova V, Menozzi C, Biddlecom A. National, regional, and global rates and trends in contraceptive prevalence and unmet need for family planning between 1990 and 2015: a systematic and comprehensive analysis. Lancet. 2013;381:1642-52. doi:10.1016/So140-6736(12)62204-1

4. World population prospects 2019: highlights. New York: UN Department of Economic and Social Affairs; 2019 (https://population.un.org/wpp/Publications/Files/WPP2019_Highlights.pdf, accessed 21 February 2021).

5. Commitment makers. Family planning 2020. Washington, DC: United Nations Foundation; 2017 (http://www.familyplanning2020.org/commitment-makers, accessed 1 March 2021).

6. Pakistan demographic and health survey 2012-2013. Islamabad: National Institute of Population Studies and Measure DHS ICF International; 2013 (http://www.nips.org.pk/abstract_files/PDHS Final Report as of Jan 22-2014.pdf, accessed 21 February 2021).

7. London summit on family planning (July 2012). Summaries of commitments. London: Department for International Development; 2013 (http://www.familyplanning2020.org/sites/default/files/London_Summit_Commitments_12-2-2013_0.pdf, accessed 21 February 2021). 
8. Pakistan demographic and health survey 2017-2018. Key indicators report. Islamabad: National Institute of Population Studies, and DHS Program ICF; 2018 (https://www.nips.org.pk/abstract_files/PDHS\%20-\%202017-18\%20Key\%20indicator\%20Report\%20 Aug\%202018.pdf, accessed 21 February 2021).

9. Zaman A, Subhan F, Mumtaz A, Khan AQ. 18th amendment \& provincial autonomy: challenges for political parties. Bi-Annual Res J, Balochistan Study Centre, University of Balochistan; 2018.

10. Wazir MS, Shaikh BT, Ahmed A. National program for family planning and primary health care Pakistan: a SWOT analysis. Reprod Health. 2013;10:60. doi:10.1186/1742-4755-10-60

11. Nishtar S, Amjad S, Sheikh S, Ahmad M. Synergizing health and population in Pakistan. J Pak Med Assoc. 2009;59(9 Suppl. 3):S3-23. PMID: 20088459

12. Zafar S, Shaikh BT. 'Only systems thinking can improve family planning program in Pakistan': a descriptive qualitative study. Int J Health Policy Manag. 2014 Nov 17;3(7):393-8. doi:10.15171/ijhpm.2014.119

13. Jacoby D. Guide to supply chain management: how getting it right boosts corporate performance. Hoboken, New Jersey: John Wiley \& Sons; 2009.

14. Chandani Y, Breton G: Contraceptive security, information flow, and local adaptations: family planning Morocco. Afr Health Sci. 2002;1:73-82. PMID: 12789120

15. Daff BM, Seck C, Belkhayat H, Sutton P: Informed push distribution of contraceptives in Senegal reduces stockouts and improves quality of family planning services. Glob Health Sci Pract. 2014 May 13;2(2):245-52. doi:10.9745/GHSP-D-13-00171

16. Sedgh G, Hussain R: Reasons for contraceptive nonuse among women having unmet need for contraception in developing countries. Stud Fam Plann. 2014;45:151-69. doi:10.1111/j.1728-4465.2014.00382.x

17. DELIVER project. Pakistan: New logistics management information system incorporates sustainability and cost savings. Arlington: US Agency for International Development; 2012 (https://publications.jsi.com/JSIInternet/Inc/Common/_download_pub. cfm?id=15745\&lid=3, accessed 21 February 2021).

18. Annual contraceptive performance report 2018-19. Islamabad: Pakistan Bureau of Statistics; 2020 (https://www.pbs.gov.pk/ content/annual-contraceptive-performance-report-2018-19, accessed 21 February 2021).

19. Qureshi SA, Hamid S, Bajwa MS: The role of contraceptive logistics management information system in provision of family planning services in the province of Sindh, Pakistan. Diversity Equality Health Care. 2017;14:34-9.

20. Family planning executive dashboard user's guide. Peshawar: Government of Khyber Pakhtunkhwa, Population Welfare Department and Department of Health; 2018 (http://lmis.gov.pk/docs/ExecutiveDashbaordGuide/ExecutiveDashboardUsersManual.pdf, accessed 21 February 2021).

21. USAID Global Health Supply Chain Program. situation analysis: contraceptive manufacturing in Pakistan. 2020 [http://lmis.gov. pk/docs/SituationAnalysisReportIndigenousProductionofContraceptives/situation_analysis_contraceptive_manufacturing_in_ pak_sep082020.pdf, accessed 21 February 2021).

22. Pakistan Logistics Management Information System. (http://www.lmis.gov.pk/index.php, accessed 21 February 2021).

23. Supply chain management: investing in contraceptive security and strengthening health systems. Baltimore: Johns Hopkins University, HIP Family Planning High Impact Practices; 2020 (http://www.fphighimpactpractices.org/briefs/supply-chain-management/, accessed 21 February 2021).

24. SEED Assessment Guide for Family Planning Programming. New York: Engender Health; 2011 (https://www.engenderhealth. org/files/pubs/family-planning/seed-model/seed-assessment-guide-for-family-planning-programming-english.pdf, accessed 21 February 2021).

25. Deliver project. Final country report: Pakistan. Arlington: US Agency for International Development; 2016 (https://deliver.jsi. com/wp-content/uploads/2017/o1/FinaCounRepo_PK.pdf, accessed 21 February 2021).

26. Recent success stories in reproductive health commodity security. New York: United Nations Population Fund; 2010 (https:// www.unfpa.org/sites/default/files/pub-pdf/success_rhcs.pdf, accessed 21 February 2021).

27. Ten good practices in essential supplies for family planning and maternal health. New York: United Nations Population Fund, Global Programme to Enhance Reproductive Health Commodity Security; 2012 (https://www.unfpa.org/sites/default/files/pubpdf/Ten\%20Good\%20Practices\%20Essential\%20Supplies_GPRHCS_web.pdf, accessed 21 February 2021).

28. SDG 3. Ensure healthy lives and promote well-being for all at all ages. New York: United Nations Department of Economic and Social Affairs; 2015 (https://sustainabledevelopment.un.org/sdg3, accessed 21 February 2021).

29. Key initiatives. Lahore: Population Welfare Department, Government of the Punjab; 2017 (https://pwd.punjab.gov.pk/system/ files/Initiatives_o.pdf, accessed 21 February 2021).

30. Basharat R. Public health supply chain systems to be digitised: SAPM health. The Nation. 19 January 2020 (https://nation.com. pk/19-Jan-2020/public-health-supply-chain-system-to-be-digitised-sapm-health, accessed 21 February 2021).

31. Mukasa B, Ali M, Farron M, Van de Weerdt R: Contraception supply chain challenges: a review of evidence from low- and middle-income countries. Eur J Contracept Reprod Health Care. 2017 Oct;22(5):384-90. doi:10.1080/13625187.2017.1394453

32. d'Arcangues CM, Ba-Thike K, Say L: Expanding contraceptive choice in the developing world: lessons from the Lao People's Democratic Republic and the Republic of Zambia. Eur J Contracept Reprod Health Care. 2013;18:421-34. doi:10.3109/13625187.2013 .826796 